\title{
INTRODUKSI TEKNOLOGI BIOCHAR UNTUK MEMPERBAIKI LAHAN KRITIS MILIK PETANI WILAYAH MAGERSARI DI KABUPATEN TUBAN, PROPINSI JAWA TIMUR
}

\author{
Widowati $^{1 *}$, Agnes Quartina Pudjiastuti², Ana Arifatus Sa'diyah ${ }^{2}$ \\ ${ }^{I}$ Program Studi Agroteknologi, Fakultas Pertanian, Universitas Tribhuwana Tung gadewi, Malang, Indonesia \\ ${ }^{2}$ Program Studi Agribisnis, Fakultas Pertanian, Universitas Tribhuwana Tung gadewi, Malang, Indonesia \\ *Penulis Korespondensi : widwidowati@gmail.com
}

\begin{abstract}
Abstrak
Upay a meningkatkan produksi dan produktivitas la han pertanian saat ini bukan hal yang mudah karena ketersediaan la han pertanian yang rela tif tetap, bahkan cenderung berkurang karena berbagai faktor. Salah satu alternatif yang bisa dilakukan dalam jangka pendek adalah memperbaiki kesuburan lahan ta ndus yang selama ini digunakan masyarakat petani sebagai sumber mata pencahariannya. Tujuan dari program pengabdian kepada masyarakat bagi mitra petani a dalah mengin troduksikan teknologibiochar untuk memperbaiki la han kritis (tandus dan berbatu) dan mengevaluasi usahatan yang ada. Metodeyang digunakan untuk mencapai tujuan tersebut adalah penyuluhan dan pelatihan pembuatan biochar (teknologi), pemberian bantuan a lat pembuat biochar dan bibit tanaman, serta pendampingan kepada petani mitra di Desa Jetak, Kecamatan Montong, Kabupaten Tuban. Petani mulai memahami teknologi biochardan manfaatnya bagi usa hatani di la han kritis, menggunakan teknologi biochar, dan manajemen usahatani berbasis teknologi biochar. Petani telah sadar bahwa aplikasi biochar dapat menurunkanbiaya usahatani karena dibuat dari limbah pertanian yang tersedia berlimpah. Alat produksi biochar relatif murah dan terjangkau bagi petani yang ingin memperbaiki kondisi lahannya yang kritis.
\end{abstract}

Kata kunci: Biochar; Lahan Kritis; TeknologiSederhana.

\begin{abstract}
Efforts to increase production and productivity of agricultural land at this time is not easybecause the availability of a gricultural land is relatively fixed, and even tends to decrease due to various factors. One alternative that can be done in the short term is to improve the fertility of the barren land that has been used by the farming community as a source of livelihood. The aim of the community service program for farmer partners is to introduce biochar technology to improve critical land (barren and rocky) and evaluate existing farming. The methods used to achieve these objectives are counseling and training in making biochar (technology), providing assisting in making biochar tools and plant seeds, as well as assistance to partnerfarmers in Jetak Village, Montong District, Tuban District. Farmers are beginning to understand biochar technology and its benefits for farming on degraded land, using biochar technology, and farm management based on biochar technology. Farmers are aware that biochar application can reduce farming costs because it is made from abundant available a gricultural waste. Biochar production equipment is relatively inexpen sive and affordable for farmers who want to improve their critical land conditions.
\end{abstract}

Keywords: Appropriate Technology; Biochar; Critical Land.

\section{PENDAHULUAN}

Lahan kritis merupakan lahan tidak produktif yang lebih banyak terjadi a kibat aktivitas manusia. Penggunaan lahan yang tidak sesuai dengan kemampuannya akan menyebabkan kerusakan fisik, kimia maupun biologis tanah. Akibat selanjutnya, kesuburan tanah menjadi rendah sehingga tidak mampu menyangga kebutuhan produksi ta naman. Produksi ta naman yang lebih rendah dari kebutuhan masyarakat dalam jangka panjang akan menimbulkan bagi perekonomian baik mikro maupun makro. Menurut (Pudjiastuti et al., 2013), Pudjiastuti (2014) dan (Pudjiastuti \& Kembauw, 2018), produksi (penawaran) yang rendah sementara permintaan tinggi akan menyebabkan terjadinya pemenuhan permintaan melalui impor dan hal ini akan mengganggu neraca perdagangan.

Lahan kritis memiliki kondisi lingkungan sangat beragam tergantung pada penyebab kerusakan laha n.Lahan kritis ditandai oleh ru saknya struktur tanah, menurunnya kualitas dan kuantitas bahan organik, defisiensi hara dan terganggunya siklus hidrologi. Kondisi tersebutperlu direhabilita si dan ditingkatkan produk-tivitasnya agar lahan dapat kembali berfungsi 
sebagai suatu ekosistem yang baik atau menghasilkan sesuatu yang bersifat ekonomis bagi ma nusia.

Faktor-faktor yang menyebabkan terjadinyalahan kritis adalah: 1) genangan a ir yang terus-menerus seperti di da erah pantai dan rawa-rawa, 2) kekeringan, biasanya terjadi di daerah bayangan hujan, 3) erosi tanah atau masswasting yang biasanya terjadi di daerah dataran tinggi, pegunungan, dan daerah miring lainnya, 3) pengelolaan lahan yang kurang memerhatikan aspekaspek kelestarian lingkungan, 4) masuknya material yang dapat bertahan lama ke lahan pertanian, misalnya pla stik. Pla stik dapat bertahan 200 tahun di dalam tanah sehingga sangat mengganggu kelestarian lahan perta nian, 5) terjadinya pembekuan a ir, bia sanya terjadi di daerah kutub a tau pegunungan yang sangat tinggi, 6) masuknya zat pencemar (misal pestisida dan limbah pabrik) ke dalam tanah sehingga tanah menjadi tidak subur.

Usaha-usaha yang dapat dilakukan untuk memperbaiki la ha n kritis di antaranya: 1) Menghilangkan unsur-unsur yang meng-ganggu kesuburan la han pertanian, misalnya plastik. Dalam hal ini, proses daur ulang a tau recycling sangat diperlukan. Proses daur ulang ini juga dapat menghemat SDA yang tidak dapat diperbarui (nonrenewable). 2) Penghijauan kembali (reboisasi) daerahda erah yang tandus, terutama di da erah pegunungan. 3) Melakukan reklamasi lahan bekas pertambangan yang biasanya sangat gersang. Umumnya ditanami jenis tumbuhan yang mampu hidup di daerah tersebut, misalnya pohon mindi. 4) Memanfaatkan tumbuhan eceng gondok guna menurunkan zat pencemar yang ada pa da lahan pertanian. Eceng gondok dapat menyerapzat pencemar dan dapat dimanfaatkan untuk makanan ikan. Namun dalam hal ini pengelolaannya harus hati-hati karena eceng gondok sangat mudah berkembang sehingga dapat menganggu lahan pertanian apabila pertumbuhannya tidak terkendali. 5) Pemupukan dengan pupuk organik atau alami y aitu pupuk kandang atau pupuk hijau secara tepat dan terus-menerus. 6) Tindakan yang tegas teta pi bersifat mendidik kepada siapa saja yang melakukan kegiatan yang dapat menyebabkan terjadinya lahan kritis. 7) Pengelolaan wilayah terpadu di wilayah lautan dan daerah aliran sungai (DAS). 8) Pengembangan keanekaragaman hayati dan pola pergiliran tanaman.

Upaya memperbaiki lahan kritis mendesak untuk dilakukan karena la han pertanian yang subur semakin berkurang, sementara areal lahan kritis juga masih tergolong tinggi meskipun telah mulai berkurang. Data Direktorat Jenderal Pengelolaan Daerah Aliran Sungai dan Hutan Lindung (PDASHL) menunjukkan luas lahan kritis di Indonesia terus menurun. Pada tahun 2018, lahan kritis di Indonesia tercatat seluas 14,01 juta hektar. Pada tahun ini, salah satu sumber penyebab berta mbahnya area lahan kritis a dalah kebakaran hutan dan la han. Pemulihan la han yang rusakini memerlukan biaya sebesar Rp. 1,37 triliun (KLHK, 2018). Sebelumnya, pada tahun 2009, luas la han kritis tercatat sebesar 30,1 juta hektar, dan tahun 2014 seluas 27,2 juta hektar.

Ipteks bagi petani yang diintroduksikan untuk memperbaiki kesuburan dan produktivitas tanah dalam jangka panjang adalah menambah bahan pembenah tanah berupa biochar/arang hayati. Biochar menupakan suatu padatan berpori yang kaya akan karbon dan diha silkan dari pembakaran secara tidak sempuma dari limbah organik (biomassa). Biochar berwama hitam dan berbeda dengan arang biasa yang digunakan sebagai bahan bakar. Biochar mengandung abu yang rendah dan karbon yang tinggi, seda ngkan arang biasa mengandung abu yang tinggi dan kandungan karbonnya rendah. Biochar mempunyai stabilitas yang tinggi terhadap dekomposisi, bersifat alkali, tekstur berpori, halus, substansi yang menyerap, dan mengandung unsur hara esensial (terutama P dan K). Biochar memberi efek dalam jangka panjang dan lebih efisien dalam meningkatkan kualitas tanah. Berbeda dengan kompos a tau pupuk kandang dapat meningkatkan sifat tanah da la m jangka pendek. Namun perbaikan sifat fisik tanah liat lebih baik menggunakan kombinasi jenis biochar denga nupuk organik (Widowati et al., 2017).

Biochar merupakan bahan amandemen tanah yang sangat prospektif. Penggunaan biochar dapat memperbaiki sifat tanah dan ketersediaan unsur hara tanah da lam jangka panjang (Agegnehu et al., 2017). Penggunaan biochar dapat meningkatkan produktivitas ta nah melalui perbaikan sifat fisika, kimia(Aslam et al, 2014), (Jien \& Wang, 2013),(Li et al., 2018), (Mukherjee \& Lal, 2013), (Shaaban et al., 2018), (Wu et al., 2017), biologi tanah (Hussain et al., 2017) dan perbaikan struktur tanah (Bista et al., 2019), (Cybulaket al., 2019) serta porositas tanah (Huang et al., 2020), (Liu et al., 2018). Aplikasi biochar sangat penting untuk meningkatkan sifat fisik dan kimia tanah asam (Dume et al., 2015). Beberapa hasil penelitian menemukan bahwa penggunaan biochar dapat meningkatkan efisiensi penggunaan air (Elba shier et al., 2018) dalam usahatani melon, pemupukan nitrogen (Widowati \& Asnah, 2014). Aplikasi biochar pada media pertumbuhan meningkatkan kesuburan tanah (Hamzah \& Shuhaimi, 2018), (Krishnakumar et al., 2014), (Videga in-Marco et a l., 2020). Biochar dari sekampadi dan jerami dapat menghemat bia ya kapur, pupuk, emisi gas rumah kaca terutama di lahan kritis (Jeffery et al, 2017), (Zhang et al., 2018).Studi terbaru menunjukkan bahwa biochar dan kapur dapat efektif untuk meningkatkan sifat fisikokimia ta nah merah dan hasil gandum (Malik et a l., 2018). Dengan demikian biochar memiliki manfaat yang sangat besar dan luas, tenutama dala m memperbaiki kondisi lahan kritis a gar menjadi lahan produktif. Oleh karena itu penting untuk mengenalkan teknologi biochar kepada petani yang melakukan usahataninya di lahan kritis.

Desa Jetak, Kecamatan Montong, Kabupaten Tuban seperti daerah lainnya di Kabupaten Tuban, sebagian besar lahan usahatani merupakan daerah tandus, berbatu dan mengandalkan air hujan. Ada dua petanimuda yang tetap mengelola usahataninyameskipun lahan mereka 
termasuk ke dalam kriteria lahan kritis yang berbatu. Para petani tersebut menjadi mitra karena karakteristik yang mereka miliki. Petani pertama memiliki lahan kritis selua s 1,1 hektar. Tanaman yang dikembangkan di la han ini adalah jati emas yang berjumlah 1000 pohon yang telah berumur 13 tahun. Sa at ini dia meter pohon yang ditanam dengan jarak tanam 2 x 1 meter ini telah mencapai $25 \mathrm{~cm}$. Dulu, pada sa at tanaman jati emas masih tidak terla lu tinggi, petani mitra juga memberi kesempatan kepada beberapa petani lain untuk menggarap lahannya dengan membudidayakantanaman pangan seperti jagung, kacang tanah dan ketela pohon. Sa at ini, karena tanaman jati sudah relatif tinggi, maka tidak dimungkinkan la gi untuk mengusahakan tanaman pangan tersebut. Namun menurut salah satu petani, di antara tanaman jati dengan kond isi seperti sekarang ini, masih mungkin untuk ditanami suweg.

Petani kedua memiliki lahan kritis seluas 1 hektar. Tanaman yang dikembangkan di lahan ini adalah ta naman sawo sebanyak 500 pohon y ang masih berumur 2 tahun. Tanaman sawo sa at ini memiliki ketinggian sekitar 1 meter dengan jarak tanam 2 x 3 meter. Sebagian lahan juga ditanami pohon jati. Upaya memanfaatkan lahan tandus dengan tanaman jati memerlukan waktu yang lama. Setelah empat kali menanam pohon jati, baru kali yang keempat ini ada 300 pohonjatiyang berhasil hidup. Petani ini juga memberi kesempatan kepada 5 (lima) petani lain untuk menggarap sebagian lahannya. Para petani ini menanam ja gung dan kacang ta nah.

Tulisan ini bertujuan untuk memberi informasi tentang pengelolaan limbah pertanian dengan teknologibiochar yang bermanfaat di bidang pertanian khususnya untuk memperbaiki lahan kritis yang ditanami tanaman pangandanjati di wilayah Magersari Kabupaten Tuban.

\section{BAHANDAN METODE}

Pengabdian kepada masyarakat ini dilakukan melalui kegia tan penyuluhan, pelatihan, dan pemberian bantuan (investasi) kepada petani mitra di Desa Jetak, Keca matan Montong, Kabupaten Tuban. Secara terinci, kegia tan tersebut meliputi:

1) Penyuluhan dan pelatihan tentang perbaikan lahan kritis, oleh beberapa pakar di bidang biochar dan tanah yang memberikan wa wasan kepada petani sekaligus praktiknya tentang: pengertian dan manfaat biochar, pengenalan a lat untuk membuat biochar, pembuatan biochar dan aplikasinya, evaluasi dan analisis kualitas lahan.

2) Penyuluhan dan pelatihan tentang budidaya lahan yang optimal dengan teknologi biochar: dalam kegiatan ini didatangkan beberapa pakar di bidang budidaya lahan yang a kan memberikan wawasan kepada petani tentang budidaya lahan secara optimal sesuai kondisi lahan petani dengan teknologibiochar dan praktiknya.

3) Penyuluhan dan pelatihan tentang manajemen usahatani, dalam kegiatan ini didatangkan pakar agribisnis yang akan menjelaskan dan mempraktikkan tentang: pembukuan usahatani secara sederhana, menganalisis kelayakan usahatani secara sederhana,

4) Memberikan bantuan bahan dan alat produksi untuk pembuatan biochar

5) Memberikan bantuan bibit tanaman sesuai lahan petanidan teknologibiochar.

Setelah penyuluhan dan pendampingan kepada mitra, a kan ada perubahan dalam aspek: jumlah tanaman yang diusahakan, pemahaman petani tentang pengertian dan manfaat biochar, kemampuan petani membuat biochar, pembukuan usahatani, perencanaan usahatani dan ketra mpilan lainnya.

\section{HASIL DAN PEMBAHASAN}

Langkah awal yang dilakukan setelah pertemuan dengan petani mitra adalah membuat studi kelayakan usahatani. Tanaman yang dikaji kelayakan usahanya seca ra finansial a dalah tanaman jati (Tectona grandis) karena jenis tanaman ini dibudidayakan di lahan milik kedua mitra. Kajian ini menghasilkan kesimpulan bahwa usahatani tanaman jati layak untuk dikembangkan berdasarkan kriteria kelayakan. Keuntungan yang diperoleh selama 3 tahun (2015-2018) adalah Rp. 4,729,263.22. Penjualan minimum yang menghasilkan titik impas sebesar 125 pohon, dengan nilai penjualan impas sebesar Rp. 2.165.309,49. Usahatani inia kan lebih menguntungkan bila kesuburan tanahnya ditingkatkan dengan teknologi biochar (Widowati et al., 2018). Kegiatan selanjutnya benupa penyuluhan dan pelatihan tentang peningkatan kualitas produk dan manajemen usaha serta bantuan peralatan. Hasil pelaksanaan kegia tan tersebut dijelaskan berikut ini.

\section{Penyuluhan, Pelatihan Pembuatan dan AplikasiBiochar di Lahan Petani, Manajemen Usahatani}

Penyuluhan dan pelatihan diberikan kepada kedua mitra yang melibatkan an ggota kelompok tani salah satu mitra yang kebetulan adalah ketua kelompok tani Sanggabuana Desa Jetak. Materi penyuluhan dan pelatihan yang diberikan meliputi:

a) Pengertian dan manfaat biochar bagi la han kritis

b) Pengenalan alat dan proses pembuatan biochar

c) Aplikasi biochar dan budidaya tanaman yang optimal sesuai lahan petani

d) Analisis kelayakan usahatani

e) Penca tatan keuangan/pembukuan usahatani

Dalam kegiatan ini diberikan bantuan peralatan pembuatan biochar dan bantuan bibit tanaman sesuai dengan keinginan dan lahan petani yaitu sa wo, durian, kopi. Namun dalam kegiatan ini, diberikan bibit durian sesuaipermintaan petanikarena dianggap lebih sesuai dengan lokasi (ada petani la in yang telah menanam durian).

Penyuluhan dan pelatihan kepada mitra dan anggota kelompok tani lainnya yang bergabung dengan mitra diselenggarakan pada tanggal 11-12 Agustus 2018. Selanjutnya, petani mitra mencoba menga plikasikan 
biochar di lahannya dan menanam pepaya jenis California di dua media yaitu dengan biochar dan tanpa biochar. Petani melaporkan bahwa pertumbuhan dan produktivitas pepaya di la han dengan biochar lebih baik dibandingkan pepaya yang ditanam di lahan tanpa biochar.

\section{Bantuan Alat Pembuatan Biochar}

Petani mitra mendapatkan bantuan berupa alat pembuatan biochar sederhana sebanyak 30 unit. Ala tini bisa dimanfaatkan oleh anggota kelompok tani peserta penyuluhan dan pela tihan yang ingin membuat biochar sendiri dan mengaplikasikannya di lahan mereka. Alat sederhana ini disketsakan di Ga mbar 1 .

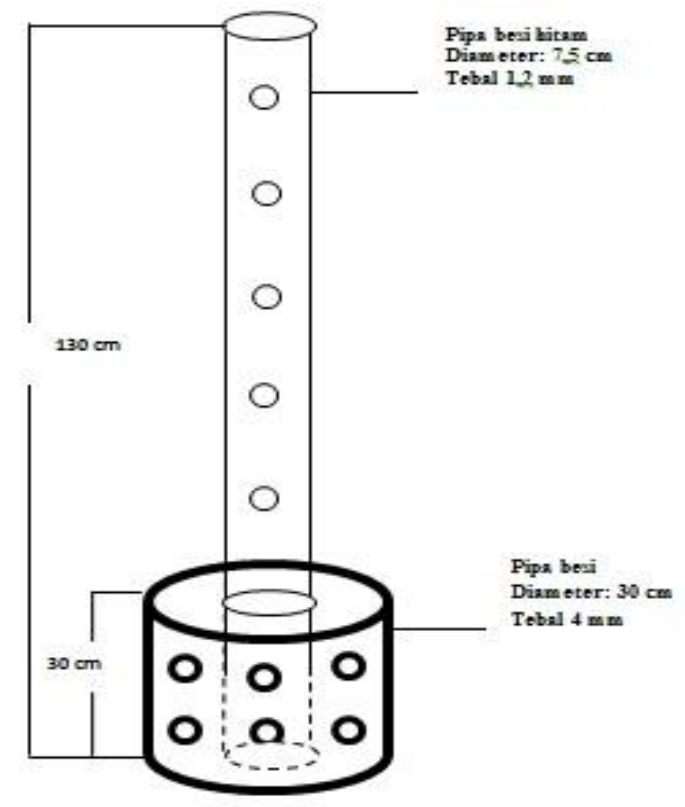

Gambar 1. Alat Sederhana Pembuatan Biochar

Alat pembuat biochar ini mengikuti rancangan alat pembuat biochar yang diproduksi BPTP Yogyakarta dengan modifikasi bahan yang lebih ta han la ma seperti yang ditunjukkan dalam sketsa. Proses pembuatan alat ini sejumlah 30 unit memerlukan waktu dua minggu. Alat pembuat biochar dikirimkan kepada kedua mitra sebelum pelaksanaan penyuluhan dan pelatihan diselenggarakan. Pengiriman alat pembuat biochar dilakukan bersama dengan 75 bibit durian sebagai ba gian dari bantuan yang diserahkan kepada mitra.

Proses pembuatan biochar adalah:

1. Menyediakan sekam, tongkol jagung (janggel), kayu atau daun-daunan kering sebagai bahan baku biochar.

2. Menempatkan alat pembuatan biochar berbahan besi yang telah diisi bahan bakar (kayu bakar atau bahan bakar la innya) di tem pat yang terbuka.

3. Menimbun alat pembuatan biochar dengan bahan bakubiochar.

4. Memanaskan bahan bakar yang telah dimasukkan dan menambahkannya bila panas mulai berkurang.

5. Membalik sekam (limbah lainnya) dengan hati-hati agar seluruh bahan baku terbakar secara merata sehingga seluruhnya berubah menjadi biochar.
6. Memisahkan a lat dengan biochar sekam (limbah lainnya) jika semua bahan baku telah berubah menjadia rang (berwarna hitam).

7. Mengumpulkan biochar sekam (limbah lainnya) dan memasukkannya ke dalam karung.

Bia ya proses pembuatan biochar ini sangat rendah (tidak a da biaya) ka rena bahan baku yang digunakan adalah limbah hasil produksi pertanian (sekam padi, tongkol jagung, daun jati kering). Bahan baku ini banyak tersedia di lokasi. Aplikasi biochar di la han milik petani cukup dilakukan hanya sekali untuk memberkan manfaat dalam jangka waktu yang relatif sangat lama. Proses yang sangat sederhana juga dengan mudah bisa dilakukan petani.

Proses pembuatan biochar dalam kegiatan pelatihan disajikan dalam rangkaian Gambar 2-5. Gambar tersebut menunjukkan langkah/proses pembuatan biochar yang berurutan.

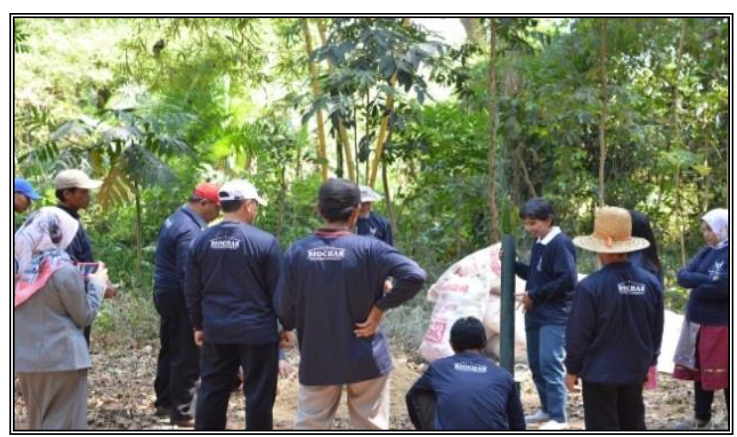

Gambar 2. Langkah 1

Alat pembuat biochar ditegakkan di tanah kemudian ditimbun dengan sekam padi yang akan diubah menjadi biochar. Bahan bakar berupa potongan kayu, daun-daun kering dan ba han la innya dimasukkan melalui cerobong dan dibakar.

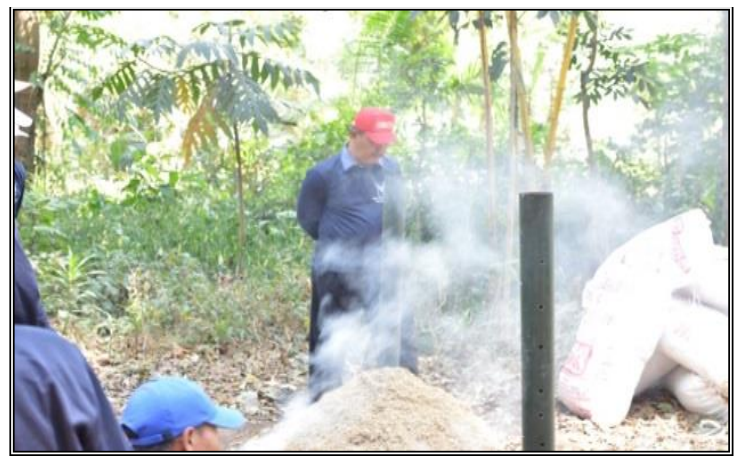

Gambar3.Langkah 2

Menyalakan bahan bakar di dalam cerobong a ga r a lat menjadi panas dan sekam padi berubah menjadi arang. Bila bahan bakar habis, maka ditambahkan bahan bakar kembali ke dalam cerobong. 

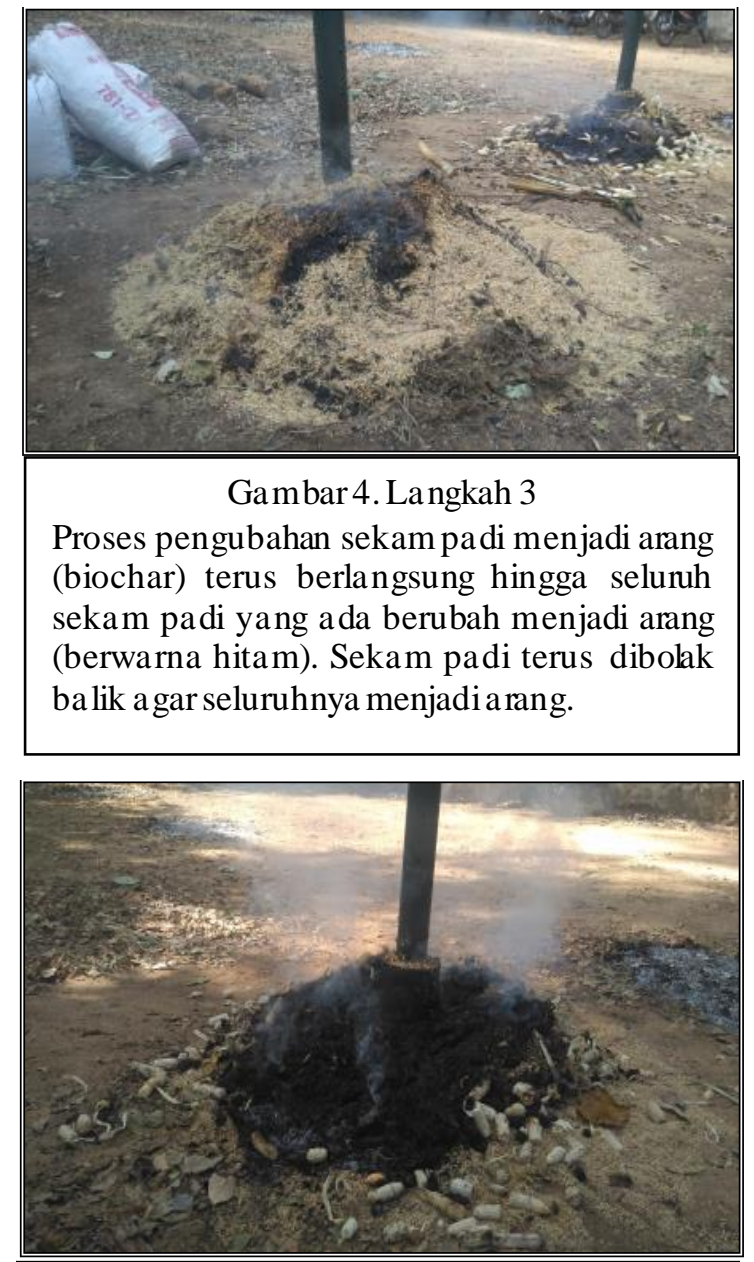

Gambar5.Langkah 4

Sebagian besar sekam padi telah benubah menjadi biochar. La ma proses tergantung pada banyaknya sekam padi. Hasil pelatihan menunjukkan bahwa proses pembakaran tiga karung sekam padi menjadi biochar membutuhkan waktu kurang lebih 3 jam.

Setelah sekam padi berubah menjadi biochar seluruhnya, maka biochar dibiarkan menjadi dingin terlebih dahulu. Selanjutnya, biochar dima sukkan ke dalam karung untuk diaplikasikan di lahan petani. Petani juga telah dilatih bagaimana cara mengaplikasikan biochar agar bisa memperbaiki lahan kritis menjadi lebih subur. Biochar sekam padi dicampur dengan pupuk kandang kemudian dimasukkan ke lahan petani dengan ukuran $100 \mathrm{~kg}$ per ha pada saat pengolahan ta nah. Untuk bisa mengevaluasi perbaikan la han, petani diminta untuk melakukan duaperlakuan yaitumenanam jagung di lahan yang diaplikasi biochar dan di lahan yang tidak diaplikasi biochar. Evaluasi kegiatan disajikan di Tabel 1.

Tabel 1.Evaluasi Hasil Kegiatan Penyuluhan dan Pelatihan.

\begin{tabular}{|c|l|l|l|}
\hline No & \multicolumn{1}{|c|}{ Aspek } & \multicolumn{1}{c|}{ Sebelum } & \multicolumn{1}{c|}{ Sesudah } \\
\hline 1 & $\begin{array}{l}\text { Jenis } \\
\text { tanaman }\end{array}$ & $\leq 2$ jenis & $>2$ jenis \\
\hline
\end{tabular}

\begin{tabular}{|c|l|l|l|}
\hline 2 & $\begin{array}{l}\text { Pengetahuan } \\
\text { tentang } \\
\text { biochar }\end{array}$ & $\begin{array}{l}\text { Tidak ada } \\
(0 \%) \text { petani } \\
\text { yang } \\
\text { mengetahui }\end{array}$ & $\begin{array}{l}\text { Semua } \\
(100 \%) \\
\text { petani } \\
\text { mengetahui }\end{array}$ \\
\hline 3 & $\begin{array}{l}\text { Pengenalan } \\
\text { alat } \\
\text { pembuatan } \\
\text { biochar }\end{array}$ & $\begin{array}{l}\text { Tidak ada } \\
(0 \%) \text { petani } \\
\text { yang } \\
\text { mengenal }\end{array}$ & $\begin{array}{l}\text { Semua } \\
(100 \%) \\
\text { petani } \\
\text { mengenal }\end{array}$ \\
\hline 4 & $\begin{array}{l}\text { Proses } \\
\text { pembuatan } \\
\text { biochar }\end{array}$ & $\begin{array}{l}\text { Tiak ada } \\
(0 \%) \text { petani } \\
\text { yang } \\
\text { mengetahui }\end{array}$ & $\begin{array}{l}\text { Semua } \\
(100 \%) \\
\text { petani } \\
\text { mengetahui }\end{array}$ \\
\hline 5 & $\begin{array}{l}\text { Cara aplikasi } \\
\text { biochar }\end{array}$ & $\begin{array}{l}\text { Tidak ada } \\
(0 \%) \text { petani } \\
\text { yang } \\
\text { mengetahui }\end{array}$ & $\begin{array}{l}\text { Semua } \\
(100 \%) \\
\text { petani } \\
\text { mengetahui }\end{array}$ \\
\hline 6 & $\begin{array}{l}\text { Pengetahuan } \\
\text { tentang } \\
\text { pembukuan } \\
\text { usahatani } \\
\text { sederhana }\end{array}$ & $\begin{array}{l}30 \% \text { petani } \\
\text { memahami }\end{array}$ & $\begin{array}{l}100 \\
\text { petani } \\
\text { memahami }\end{array}$ \\
\hline 7 & $\begin{array}{l}\text { Pengetahuan } \\
\text { tentang } \\
\text { analisis } \\
\text { kelayakan } \\
\text { usahatani }\end{array}$ & $\begin{array}{l}10 \% \text { petani } \\
\text { memahami }\end{array}$ & $\begin{array}{l}100 \% \text { petani } \\
\text { memahami }\end{array}$ \\
\hline 8 & $\begin{array}{l}\text { Investasialat } \\
\text { pembuatan } \\
\text { biochar }\end{array}$ & $\begin{array}{l}\text { Tidak ada } \\
\text { namalat }\end{array}$ & 30 alat \\
\hline
\end{tabular}

Sumber: Data primer, diolah.

Sulitnya melakukan monitoring dan memperoleh informasi tentang kondisi la han kritis milik petani, akan lebih baik dan mudah bila ada penguatan kapasitas pemerintah Desa Jetak berbasis teknologi informasi seperti yang dilakukan (Dako \& Ilham, 2019). Hal ini akan memudahkan dalam memilih petani mitra yang lebih banyak dalam kegiatan abdimas selanjutnya.

\section{KESIMPULAN}

Teknologi biochar merupakan upaya untuk mengelola limbah pertanian secara mudah, murah, dan terjangkau bagi masyarakat. Penerapan biochar di lahan kritis sangat bermanfaat untuk memperbaiki kualitas lahan kritis yang ditanami tanaman pangan danjatidi wilayah Magersari Kabupaten Tuban. Perubahan biomasa (limbah pertanian) menjadi biochar dengan teknologi yang sederhana dan aplikasinya di lahan kritis dapat meningkatkan produktivitas tanaman pangan. Di masa mendatang diharapkan semakin banyak limbah pertanian yang dijadikan biochar. Penerapan biochar berimplikasi pada peningkatan produktivitas tanaman dan lahan-lahan suboptimal. Keunggulan biochar sebagai bahan pembenah tanah yang relatif tahan terha dap dekomposisi bahan organik akan mendukung keberlanjutan sistem produksi tanaman. 


\section{UCAPAN TERIMAKASIH}

Terimakasih kepada DRPM Ristekdikti yang telah mendanai kegia tan pengabdian kepada masyarakat ini dan LPPM Universitas Tribhuwana Tunggadewi. Secara khusus, ucapan terimakasih juga disampaikan kepada petani mitra dan perangkat Desa Jetak Kecamatan Montong Kabupaten Tuban yang telah berkontribusi besar sehingga kegiatan pengabdian kepada masyarakat bisa terselenggara dengan baik dan tepatwaktu.

\section{DAFTAR PUSTAKA}

Agegnehu, G., Srivastava, A. K., \& Bird, M. I. (2017). The role of biochar and biochar-compost in improving soil quality and crop performance: A review. Applied Soil Ecology, 119(June), 156170. https://doi.org/10.1016/j.apsoil.2017.06.008

Aslam, Z., Khalid, M., \& Aon, M. (2014). Impact of Biochar on Soil Physical Properties. Scholarly Journal of Agricultural Science, 4(5), 280-284. https://doi.org/10.1111/j.13652486.2009.02044.x.Novak

Bista, P., Ghimire, R., Machado, S., \& Pritchett, L. (2019). Biochar Effects on Soil Properties and Wheat Biomass vary with Fertility Management. Agronomy, 9(623), https://doi.org/10.3390/agronomy 9100623

Cybulak, M., Sokolowska, Z., \& Boguta, P. (2019). Impact of Biochar on Physicochemical Properties of Haplic Luvisol Soil under Dif ferent Land Use: Experiment, A Plot. Agronomy, 9(531), 16.

Dako, A. Y., \& Ilham, J. (2019). Penguatan Kapasitas Pemerintah Desa Dunggala Kecamatan Tibawa Menuju Desa Berbasis Information and Communication Technology. Jurnal Pengabdian Kepada Masyarakat, 25(3), 144. https://doi.org/10.24114/jpkm.v25i3.14605

Dume, B., Berecha, G., \& Tulu, S. (2015). Characterization of Biochar Produced at Different Temperatures and its Effect on Acidic Nitosol of Jimma, Southwest Ethiopia. International Journal of Soil Science, 10(2), 6373. https://doi.org/10.3923/ijss.2015.63.73

Elbashier, M. M. A., Xia ohou, S., Ali, A. A. S., \& Mohmmed, A. (2018). Effect of digestate and biochar amendments on photosynthesis rate, growth parameters, water use efficiency, and yield of Chinese Melon (Cucumis melo L.) under saline irrigation. Agronomy, 8(22), 11. https://doi.org/10.3390/agronomy 8020022

Hamzah, Z., \& Shuhaimi, S. N. A. (2018). Biochar. Effects on crop growth. IOP Conference Series: Earth and Environmental Science, 215. https://doi.org/10.1088/17551315/215/1/012011

Huang, L., Gu, M., Yu, P., Zhou, C., \& Liu, X. (2020). Biochar and vermicompost amendments affect substrateproperties and plant growth of basil and tomato. Agronomy, 10(2), 12. https://doi.org/10.3390/agronomy 10020224
Hussa in, M., Farooq, M., Nawaz, A., Al-Sadi, A. M., Solaiman, Z. M., Alghamdi, S. S., Ammara, U., Ok, Y. S., \& Siddique, K. H. M. (2017). Biochar for crop production: potential benefits a nd risks. In Journal of Soils and Sediments (Vol. 17, Issue 3). https://doi.org/10.1007/s11368-016-1360-2

Jeffery, S., Abalos, D., Prodana, M., Bastos, A. C., Van Groenigen, J. W., Hungate, B. A., \& Verheijen, F. (2017). Biochar boosts tropical but not temperate crop yields. Environmental Research Letters, 12(5). https://doi.org/10.1088/17489326/aa67bd

Jien, S. H., \& Wang, C. S. (2013). Effects of biochar on soil properties and erosion potential in a highly wea thered soil. Catena, 110(November 2013), 225-233. https://doi.org/10.1016/j.catena.2013.06.021

KLHK. (2018). Status Hutan dan Kehutanan Indonesia 2018. Kementerian Lingkungan Hidup dan Kehutanan RI.

Krishna kumar, S., Rajalakshmi, A. G., Bala ganesh, B. Manikandan, P., Vinoth, C., \& Rajendran, V. (2014). Impact of Biochar on Soil Health. International Journal of Advanced Research, 2(4), 933-950.

Li, Y., Hu, S., Chen, J., Müller, K., Li, Y., Fu, W., Lin, Z., \& Wang, H. (2018). Effects of biochar application in forest ecosystems on soil properties and greenhouse gas emissions: a review. Journal of Soils and Sediments, 18(2), 546-563. https://doi.org/10.1007/s11368-0171906-y

Liu, Y., Lona ppan, L., Brar, S. K., \& Yang, S. (2018). Impact of biochar amendment in agricultural soils on the sorption, desorption, and degradation of pesticides: A review. Science of the Total Environment, 645(September), 60-70. https://doi.org/10.1016/j.scitotenv.2018.07.099

Malik, Z., Yutong, Z., ShengGao, L., Abassi, G. H., Ali, S., Imran khan, M., Kamran, M., Jamil, M., AlWabel, M. I., \& Rizwan, M. (2018). Effect of biochar and quicklime on the growth of wheat and physicochemical properties of Ultisols. Arabian Journal of Geosciences, 11(17), 1-12. https://doi.org/10.1007/s12517-018-3863-1

Mukherjee, A., \& Lal, R. (2013). Biochar Impacts on Soil Physical Properties and Greenhouse Gas Emissions. Agronomy, 3(2), 313-339. https://doi.org/10.3390/agronomy3020313

Pudjiastuti, A. Q. (2014). Perubahan Neraca Perdagangan Indonesia Sebagai Akibat Penghapusan Tarif Impor Gula. Agriekonomika, 3(2), 106-116.

Pudjiastuti, A. Q., Anindita, R., Hanani, N., \& Kaluge, D. (2013). Effects of Sugar Price Increase in Indonesia. Oeconomica, 58(1), 28-39. https://doi.org/http://studiaoeconomica.ubbcluj.r o/volumes.html

Pudjiastuti, A. Q., \& Kembauw, E. (2018). SugarPrice Policy and Indonesia's Tra de Ba lance. Journal of Advanced Research in Law and Economics, 8(8). https://doi.org/10.14505/jarle.v8.8(30).26 
Shaaban, M., Van Zwieten, L., Bashir, S., Younas, A. Núñez-Delgado, A., Chhajro, M. A., Kubar, K. A., Ali, U., Rana, M. S., Mehmood, M. A., \& Hu, R. (2018). A concise review of biochar application to a gricultural soils to improve soil conditions and light pollution. Journal of Environmental Management, 228(September), 429-440.

https://doi.org/10.1016/j.jenvman.2018.09.006

Videga in-Marco, M., Marco-Montori, P., MartíDalmau, C., del Carmen Jaizme-Vega, M., Manyà-Cervelló, J. J., \& García-Ramos, F. J. (2020). Effects of biochar application in a sorghum crop under greenhouse conditions: Growth parameters and physicochemical fertility. Agronomy, 10(104), 17. https://doi.org/10.3390/agronomy 10010105

Widowati, \& Asnah. (2014). Biochar Can Enhance Pota ssium Fertilization Efficiency and Economic Feasibility of Maize Cultivation. Journal of Agricultural Science, 6(2), 24-32. https://doi.org/10.5539/jas.v6n2p24

Widowati, Pudjiastuti, A. Q., \& Sa'diyah, A. A. (2018). Kela yakan Usaha Tanaman Jati. Agribisnis Dan Pengembangan Ekonomi Perdesaan V, 153-159.

Widowati, Sutoyo, Iskandar, T., \& Karamina, H. (2017). Characterization of biochar combination with organic fertilizer: the effects on the physical properties of some soil types. Bioscience Research, 14(4), 955-965. www.isisn.org

Wu, S., He, H., Inthapanya, X., Yang, C., Lu, L., Zeng, G., \& Han, Z. (2017). Role of biochar on composting of organic wastes and remediation of contaminated soils - a review. Environmental Science and Pollution Research, 24(20), 1656016577. https://doi.org/10.1007/s1 1356-0179168-1

Zhang, Y., Liu, Y., Zhang, G., Guo, X., Sun, Z., \& Li, T. (2018). The effects of rice straw and biochar applications on the microbial community in a soil with a history of continuous tomato planting history. Agronomy, 8(5), 13. https://doi.org/10.3390/agronomy 8050065 